\title{
A Combined Model for Continuous Intention to Use E-Learning System
}

\author{
https://doi.org/10.3991/ijim.v15i03.18953
}

\author{
Ragad M Tawafak ${ }^{(凶)}$, Sohail Iqbal Malik, Roy Mathew, \\ Mohammed Waseem Ashfaque, Jasiya Jabbar, Maryam Nasser AlNuaimi, \\ Abdalla ElDow \\ Al Buraimi University College, Al Buraimi, Oman \\ raghadQbuc.edu.om \\ Ghaliya Alfarsi \\ Al Buraimi University College, Oman \\ Universiti Tenaga Nasional, Kajang Selangor, Malaysia
}

\begin{abstract}
E-learning systems installed in educational institutions have increased the efficiency of educational processes over the years. E-learning, however, has faced many factors affecting the continuous intention of teachers and students to use e-learning, such as student satisfaction, productivity, and academic success. Therefore to improve academic success, there is a need for institutions to enhance their e-learning programs. Thus the primary objective of this thesis is to construct a composite. This research focuses on advancing e-learning to boost students' continuous trying to use e-learning to increase students' understanding and academic performance. Data were collected using questionnaires returned to determine their e-learning feedback by 295 undergraduates from four universities in Oman, after which (PLS-SEM) used e-learning to assess their ongoing trial of using e-learning. The facts demonstrate that the variables are essential for the continuing decision to use e-learning.
\end{abstract}

Keywords-E-learning, PLS-SEM, TAM, ECT

\section{Introduction}

The system of e-learning is for learning that helps, supports learning in the educational sector by using electronic technology $[1,2]$. Therefore, it applies to any course offered by an online system, or material, or program. E-learning aims to incorporate new awareness of the technology used in institutions of higher education. The e-learning framework, through web-based technology and e-learning activities, is growing to promote active learning collaboration among students. This practice is used to extract the advantages of enhancing the knowledge delivery measured by the continuing option to use e-learning according to the students' satisfaction, academic success, and effectiveness [3]. According to Tawafak [3], it is clear that the technology utilization in 
learning and evaluation allows students to work in limitless time leading to peer assistance, instructor feedback, and collaboration that triggers learning and evaluation as a learning outcome for students. Besides, the findings provide teachers with knowledge about their students' learning success and their involvement in the continuous objectives of using e-learning. This use of e-learning apps improves students' confidence and increases their understanding and willingness to use technology to facilitate learning and continuous use. Earlier e-learning research performed by $\mathrm{Wu}$ [4] argued that the existing e-learning studies are more concerned about the features related to teachers' efficiency and their experience as a primary factor without focusing on the continuous intention of using the systems. Similarly, studies carried out by Wu, Strang \& Tawafak $[4,5,27]$ stated that fewer reviews were found to focus on the academic performance of student learning outcomes with student satisfaction, which they used as dependent factors to derive the continuous e-learning system utilization.

For the current time, still, there is missing in studies that provide significant results on the effectiveness of e-learning system for both students and teachers at the same time. Besides, the recommendations from Alraimi, Tawafak \& Karnouskos [13, 14, 15] to develop a model using the standard theories of model acceptance that evaluate the elearning system performance. What are the essential elements used and the significant relationships between critical factors? Furthermore, this study highlights the need to enhance an adaptation model by integrating more than two models to improve student satisfaction and performance using e-learning systems.

Therefore this study focuses on the ongoing objective of examining positive factors derived from TAM, partial ECT, and the variation of the models proposed by Hone, Huang, Joo \& Tawafak [6, 7, 8, 9, 28], using a system of e-learning. On the other hand, this study offers flexibility and independence to teachers and students to choose the most effective e-learning system to promote teaching and to learn through the objectives towards Continuous use of e-learning methods. To this end, this study's emphasis and commitment are to focus on the theoretical creation of a combined e-learning model with TAM and partial ECT variables that can be modified to reinforce the continued objective of using the e-learning method in the field of education. This analysis also examines the relationship of nominated models between independent and dependent factors[29].

To note three significant issues, this research subject articulated itself. The first problem is about an ongoing cause, the lack of research Use an e-learning system to use. The second issue is the absence of links between e-learning variables to determine student satisfaction and the continued objective of increasing academic success by using e-learning systems[8]. The third issue is the need to construct an enhanced paradigm for the continuing alternative of using e-learning systems, articulating the fundamental objectives as follows:

i. Identify the variables impacting the ongoing intent to use the method of e-learning.

ii. To build a combined model that explores the factors affecting the continuous intention of higher education institutions to use the e-learning system.

iii. Validating the built model with methods for statistical analysis. 
This study is divided into several sections. Section two; pointed to a literature review for all courses used to identify the essential related factors of acceptance models. Besides, section three; refers to the definitions of the elements used for this study. Also, Section four; used to highlights the causal relationships between model factors. Section five; provide the framework proposed to develop the combined model. Section six; considered the hypotheses for this research model. Section seven; was designed to explain the findings and path value results. Finally, the study ends with the morals of fundamental research and future recommendation.

\section{$2 \quad$ Literature Review}

In this section, four different models suggested by Hone, Huang, Tawafak, Joo \& Ioannou $[6,7,8,9,10]$ respectively used to explain the factors that have a direction and in guiding impact on continuous intention to the utilization of a system of e-learning. According to Tawafak $[12,30]$, the potential of using e-learning technologies continuously can enhance collaboration and communication among the students and shared knowledge and ideas to improve their academic performance. However, those studies lacked a theoretical base. There are different studies pointed to use a variety of standard models as TAM, ECT to validate a combined model for e-learning system $[8,20,21$, $26]$. On the other hand, still, these studies used limited elements of critical factors. Nevertheless, the elements impact and refection provided less essential factors either for teachers or students.

The consequence of this acceptance process is establishing an ongoing intention to use an e-learning framework that uses the same acceptance factors for e-learning. Furthermore, additional variables, such as the students' happiness and academic performance[2], the efficacy of the e-learning framework, which involves factors relating to course content [19], is another common factor. The recommendations made by Tawafak $\&$ Liu [8, 25, and 31] on how the standard of e-learning can improve as follows:

i. Improving the e-learning framework to facilitate the development of the course material of each student, to enhance the continuous intention to access and use elearning.

ii. Using technology-enhanced university learning by rising e-learning adoption to enhance student satisfaction with their academic success is essential for improving continuous e-learning purposes.

\subsection{Technology Acceptance Model (TAM)}

Parameters of smoothness of using technology can indicate social influence pointing to the way of communication and information knowledge progress between students using the TAM model. The previous models on TAM comprise of initial acceptance and satisfaction as outcome factors. Ioannou [10] proposed applying the adopted TAM, which suggested that the relations between system use and benefit outcomes through 
academic performance can achieve in e-learning. In this study [18, 26, 34, 35], the authors focus on motivating students towards as an influence of the initially TAM on the constant intention to use without considering any additional regression and feedback of effectiveness of other factors related to the educational process as content satisfaction towards the continuous intention to use the e-learning process.

\subsection{Expectation-Confirmation Theory (ECT)}

The ECT theory was also combined in this study through the factors of usefulness, happiness, and constant use perceived. The peer support factor refers to the type of confirmation that could be predicted from peers to peer discussion on the student's activities $[14,32]$ and also look for support by sharing knowledge between students [15, 33]. Teacher support refers to the link and conversation between the teacher and students to explain the material and discuss assessment feedback [14].

There should be a proper purpose for the use of technology and e-learning. Another study $[9,22,28,3,15]$ ECT suggested based on these results $[6,9,22]$, as well as to strengthen the continuous intent to use the e-learning process [28].

\section{$2.3 \quad$ Multi-E-learning models}

Previous studies $[7,8]$ have shown the model factors for course content to improve an e-learning model [11]. Also, another study by Hone [6], in which the model justified the factors, course content, and effectiveness that significantly influence the continuity of outstanding work. Therefore, their studies targeted the regression of content and usefulness to teachers and students' benefit more than focusing on continuous intention to use the e-learning process $[6,7,8,31]$.

Each level is essential to react to these instructions. In the first step, e-learning is based on the continuous intent to inspire students as active users using the e-learning platform. The second stage involves teachers' teaching methods in the material offered by the courses and the experience of teachers in the use of integration of teaching technology and assessment towards the continued use of the e-learning process. Also, the level of satisfaction obtained from students with the framework is validated. Also, the productivity and academic performance factors linked to the usability and growth of elearning for the continuous purpose of using e-learning systems [2] have been established. The e-learning framework helps teachers increase student comprehension, peer debate, enhance information sharing and the growth of skills [20,13,27], and explain how to boost technology outputs to face main challenges.

Conversely, other studies improve student learning on internal and external variables such as course materials [13]. Although the study results provided useful information and experience in the field of teaching, the authors of this study did not consider the continued purpose of using the method to be important in their analysis. Their key finding on the usefulness of the factor course content is the incorporation of new knowledge to improve educational practice [9] further. The results show a significant outcome that affects the continuous use of the device. In the end, the analysis suggested by TAM 
[10] and part of the ECT model has merged with the method's continued use of e-learning.

Processes in social community services can directly affect student productivity, trust, and performance [36, 27]. For this reason, by the use of three, this study proposed developing a combined model expected acceptance models benefits. In combination with each essential element, these three models can combine to improve the understanding level of higher education students $[37,18]$. Furthermore, the integrated model will evaluate the social acceptance for this new revolution of the learning process to highlight the essential elements used for gaining both student and teacher [38]. The next section explains the factors used for a combined model and declaration of its importance and impact of each element to enhance the continuous intention to use e-learning.

\section{Factors Used in This Study}

There are 34 academic articles from journals and conference proceedings from the open database related to this field. These articles used to assess and identify the most influential factors of continuous intention used by different e-learning systems to benefit from the constant choice to use e-learning system. These different types of models work on the enhancement of the e-learning model $[14,39]$. They were using the adopted TAM and partial adoption of ECT to aid in universities' continuous intention. The most frequent factors which Perceived utility (PU), perceived ease of use (PEOU), course content (CC), behavioral intention (BI), student satisfaction (SS), academic performance (AP), effectiveness (EFF), and continuous intention to use (CI).

\subsection{Perceived Usefulness (PU)}

"People's thoughts on how emerging technology can enhance their learning performance" reflects the findings of both studies have shown that the PU is a crucial factor illustrating the progress of using the e-learning system for educational purposes.

\subsection{Ease of Use Perceived (PEOU)}

PEOU is described as the rate of students feeling that there is no need for effort to use the application of e-learning models (PEOU) attempts to investigate by considering student expectations.

\subsection{Course Content (CC)}

Course content is defined as the contents where students believe the application of e-learning model content can support their needs [7, 8]. The e-learning system allows online technology course content to be uploaded online and downloaded by students who can also access a password and submit their assignments and project outcomes [7, 8]. Factor individual characteristics refer to factor course content from sources [11], [19], [20,42] to be utilized properly. Wiki chat acts as an e-learning tool to improve 
student learning outcomes - the paper combined using wiki chat and course content effectiveness with the perception of student learning needs. Findings from the study revealed that Wiki chat's course content factor promotes student peer conversation within student groups in a significant result. The indicator from Alraimi, Tawafak [13, 20 ] shows that course content is used effectively to improve the CI of e-learning. Therefore, e-learning systems such as Wiki chat can increase the speed of accessing and transferring learning materials and simplify the transfer of knowledge from teacher to students in the continuous intention to use through the whole system activation.

\subsection{Behavior Intention (BI)}

The students' behavioral intent is determined by the perceived usefulness [21, 43]. Venkatesh [22] mentioned that behavioral intention clarified students' intention to either use continuously or adopt the e-learning system. TAM identified PU and PEOU as factors influencing the e-learning system. Besides that, factors influenced by the BI factor CI of the system, according to other studies' findings. Tawafak [21] suggested that any technology can be effectively deployed and based on behavioral intention values, such as the intention to use, which can be why teachers and students utilize technology to influence e-learning effectiveness [18].

\subsection{Academic Performance (AP)}

AP is defined as performing student activities to improve their grades using the application model. Similarly, the academic performance factor refers to the students' performance of e-system use and technology facilities [2, 1, 7, 8, 21, 11]. Behavioral intention influences academic performance with PU and PEOU towards the system use [10]. The improvement of academic performance is one aspect that can affect continuous intent to use the e-learning method. Several methods for online communication provided by education technology: Wiki chat and different Google services [19], which aid in managing online courses and try to evaluate continuous use with limited factors of communication.

\subsection{Student Satisfaction (SS)}

Student satisfaction is defined as the course content's satisfaction [1, 2, and 21]. Moreover, happiness refers to the feedback obtained from knowing the students' satisfaction, self-efficacy, and performance [23, 44]. [17] explored the relationship between students' yielded satisfaction aligned with the continuous intention to use computer devices with technologies. The strengthens the process of e-learning and promotes contact between instructors, teachers, students, and the students themselves. Student satisfaction often offers community suggestions or personal comments to boost students' satisfaction with a lower rating in the assessment.

The student satisfaction factor is an essential factor in the educational process that uses several technologies [21]. Schmid [24] re-analyzed the influence of perceived impact on e-learning. Their study's findings revealed that technology improved student 
learning's average satisfaction based on a university dataset used to measure self-evaluation effectiveness through an e-learning system. Student satisfaction has been proposed as necessary in scholarly work by Venkatesh, Davis, and Tawafak \& Malik [22, 16,26 , and 45] through the influence of PEOU and PU of TAM.

\subsection{Effectiveness (EFF)}

Effectiveness is defined as the university's assessment scalability to measure the practical assessment of the ongoing intention of using the e-learning system for different students [19, 1,2,11]. Researchers [24] mentioned an increase in the effectiveness and student satisfaction when their learning is facilitated with technology. The results from a combined dataset revealed a rise in the self-evaluation, assessing the significant measure of the students' education for the e-learning system [24]. Hence, it is evident that the use of multiple innovative technologies can improve students' performance with the help of applications that developed students' skills and knowledge and further assisted teachers in teaching. This study focuses on increasing effectiveness and satisfaction while extending their effects to include the influence on the continuous intention of system use [28].

\subsection{Continuous Intention to Use (CI)}

The continuous purpose is defined as the ongoing intention of using the e-learning system to enhance their learning abilities [2]. Ongoing intention to use means to justify ECT's satisfaction factor and the behavioral purpose of TAM. Liu and Tawafak [25, 26] explored the usage of video blogs and Wiki to optimize the intention to use systems with student satisfaction in universities continuously. Hone [6] further attempted to investigate how video learning and Face-to-face contact will increase university students' learning output and keep the continuous use of learning activity and make its purpose alive and flourishing. The system used by the authors relied on the use of Web 2.0 technologies to help the teaching process[23, 29].

\section{$4 \quad$ Extracting Causal Relationship between Factors}

Accordingly, researchers such as Liu, Eldow, Engelbrecht, MacDonald \& Tawafak $[25,18,1,2$, and 30$]$ believed that the effects of e-learning on assessments and teaching with continuous intention to use vary based on different factors. For instance, some research concentrates on student motivation, appraisal, social impact, and engagement in learning through the continuous intention-to-use model $[16,2,11]$. Other studies are more concerned with how academic success, assistance, and community impact can enhance as the critical reasons for continuous use [11]. Simultaneously, some researchers are more interested in exploring the perception, experience, circumstances, and attitude of the ongoing purpose of using the e-learning framework for measuring [22, 7 , $8,31]$. Table 1 illustrates the causal link between factors relationship based on the scholars of each one. 
Table 1. Causal Relationships from Literature

\begin{tabular}{|l|l|l|c|}
\hline \multicolumn{1}{|c|}{ Factors } & \multicolumn{1}{|c|}{ Causal Link } & \multicolumn{1}{c|}{ Original Theory } & Recent Studies \\
\hline \multirow{2}{*}{ Perceived usefulness } & PU $\rightarrow$ BI & TAM & {$[16,13,17,5]$} \\
\cline { 2 - 4 } & PU $\rightarrow$ SS & ECT & {$[5,8,13,39]$} \\
\hline \multirow{3}{*}{ Perceived ease of use } & PEOU $\rightarrow$ PU & TAM & {$[16,4,10,21]$} \\
\cline { 2 - 4 } & PEOU $\rightarrow$ BI & TAM & {$[16,18,21,33]$} \\
\cline { 2 - 4 } & PEOU $\rightarrow$ SS & ECT & {$[4,18,34,45]$} \\
\hline Course Content & CC $\rightarrow$ EFF & E-Learning & {$[7,8,6,37,45]$} \\
\hline Behavioral Intention & BI $\rightarrow$ AP & E-learning & {$[7,24,36,43]$} \\
\hline Effectiveness & EFF $\rightarrow$ CI & E-learning & {$[10,25,44,29]$} \\
\hline Academic Performance & AP $\rightarrow$ CI & E-Learning & {$[24,9,21,35]$} \\
\hline Student Satisfaction & SS $\rightarrow$ CI & ECT & \\
\hline
\end{tabular}

\section{$5 \quad$ Research Hypotheses}

The hypotheses research developed actors identified from the literature. TAM and part of The ECT model are used as a useful theoretical model to analyze students' continuous purpose to use systems for e-learning. Previous studies found that the probability of success has a positive association with the behavioral goal of consistently using e-learning.

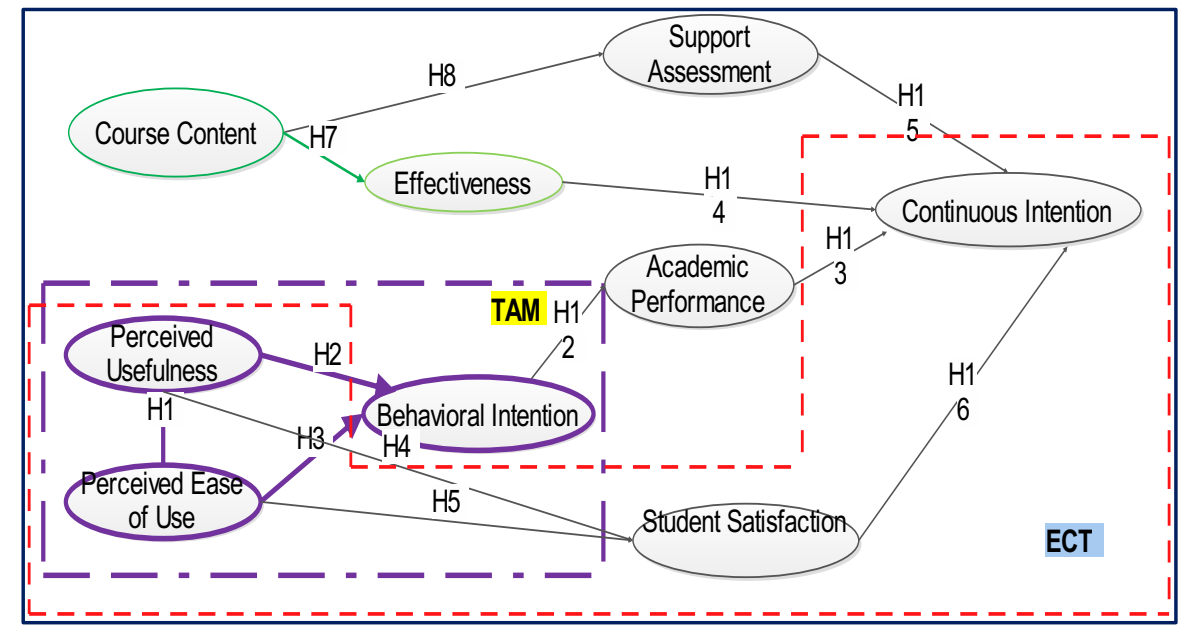

Fig. 1. Research Model

According to Davis [16], through expressly or implicitly using the model system through TAM factors $[35,13,17,40]$, where PEOU correlated with PU in PEOU has a positive effect PUU through the use of e-learning. BI may directly influence these factors and therefore indirectly influence the CI of e-learning systems. 
These three variables, namely PU, PEOU, and BI, are the critical factors for determining the continuation of an e-learning system. However, these factors are still insufficient to demonstrate the importance of the continuous intention to use e-learning unless they are related to other hybrid factors. The mixed elements collected from another type of technology tested to identify the positive impact of various factors on continuous intention enhancement $[6,7]$. Therefore the hypotheses established as below:

- H1: A significant influence on perceived ease of use and perceived utility.

- H2: A massive effect of perceived ease of use and perceived utility and purpose to behave.

- H3: A significant influence on perceived ease of use and behavioral intent.

- H4: A considerable effect of perceived utility and student satisfaction.

- H5: A significant impact on the perceived ease of student satisfaction.

- H6: A significant influence from the content of the productivity course.

Another aspect describes how the e-learning system's course content would impact the continuous goal of using the e-learning approach to provide electronic educational resources such as PowerPoint slides, files, and videos. Current revolutionary frameworks focused on e-learning principles that employ advanced, closely connected chat, file, and automated exam technologies to meet the learning and teaching needs of a system's increasingly large number of continuous intentions [26, 33]. The authors' evaluation based on the usefulness of the robust academic success factor was introduced to promote e-learning on an ongoing basis. Thus, this research aims to establish that by using academic performance as a mediator factor, certain variables have affected the endless choice of e-learning. This research seeks to find a significant link between the academic versions that implicitly suggest the influence of continuous purpose and enhancement.

Researchers such as $[18,43]$ have used TAM's mediator factor, such as the BI factor, as the main character, based on computer-based web-based survey models, as an efficient and widely agreed approach to the ongoing goal of using systems for e-learning. Their analysis showed that academic performance was significantly influenced by the perceived usefulness, ease of use, and user satisfaction. The positive impact on constant motivation, however, was not taken into account by the report. The hypotheses are, therefore defined as follows:

- H7: A meaningful impact between academic success and behavioral intent.

- H8: A significant impact between academic success and continuous purpose.

- H9: A significant influence between efficacy and continuous purpose.

- H10: A significant influence between the happiness of students and continuous purpose.

This research presents ten theories that will discuss the continuous purpose of applying e-learning activities.

The system of implementing e-learning should use in the investigation. The study used is TAM, and a portion of ECT models used in postulating the hypotheses. 


\section{$6 \quad$ Findings and Discussion}

This section highlights the characteristic findings from the combined model that has been tested in PLS-SEM. These results are characterized by 1) communication skills and 2) incorporation of the e-learning platform, which strengthens the ongoing intent to use e-learning systems. The findings indicate robust frameworks for performance, perceived value, ease of use, students' satisfaction, and behavioral intention variables in communication skills.

Based on other examples of technology used, the e-learning system contains different teaching tools and assessment methods. Similar to the findings of previous researchers $[18,26]$, many variables are apparent, such as course material, ease of use perceived, and utility perceived. To improve the accuracy of outcomes in the continuous intention to use, these variables should integrate.

\subsection{Participant Demographics}

This section presents Table 2 offers the demographic profiles of the respondents.

Table 2. Participants' demographic characteristics

\begin{tabular}{|c|c|c|c|}
\hline Field & Description & Number & Percent \\
\hline Participant & Total & 295 & $100 \%$ \\
\hline \multirow[t]{4}{*}{ Major } & IT & 147 & $47.9 \%$ \\
\hline & Engineering & 71 & $23.1 \%$ \\
\hline & LAW & 77 & $25.1 \%$ \\
\hline & Other & 12 & $0.04 \%$ \\
\hline \multirow[t]{3}{*}{ Degree } & Diploma & 99 & $32.2 \%$ \\
\hline & High diploma & 44 & $14.3 \%$ \\
\hline & Bachelor & 164 & $53.4 \%$ \\
\hline \multirow[t]{2}{*}{ Gender } & Male & 134 & $43.6 \%$ \\
\hline & Female & 173 & $56.4 \%$ \\
\hline \multirow[t]{2}{*}{ Financial Assistance/Scholarship } & Government & 191 & $66.1 \%$ \\
\hline & Private & 98 & $33.9 \%$ \\
\hline \multirow[t]{3}{*}{ Computer skill competency } & Very High & 144 & $47.4 \%$ \\
\hline & High & 132 & $43.4 \%$ \\
\hline & Low & 28 & $9.2 \%$ \\
\hline \multirow[t]{3}{*}{ How often do you use the application of e-learning } & Often & 131 & $43 \%$ \\
\hline & Sometimes & 151 & $49.5 \%$ \\
\hline & Never used & 23 & $7.5 \%$ \\
\hline \multirow[t]{3}{*}{ Age } & $18-21$ & 131 & $42.7 \%$ \\
\hline & $22-26$ & 125 & $40.7 \%$ \\
\hline & Above 26 & 51 & $16.6 \%$ \\
\hline
\end{tabular}

The questionnaire survey measured based on the Likert's 5-point scale was ranged from 1 to 5, where one strongly disagreed, and five strongly agreed. Then, PLS-SEM used the Smart PLS software to evaluate the results of the survey. The names of six independent factors are shown in Figure 1: 1) Perceived utility, 2) Perceived ease of 
use, 3 ) Items 4, 4, and 5 included in the course material. Figure 1 also shows six contingent variables, namely 1) effectiveness, 2) behavioral intention, 3) academic success, 4) student satisfaction, and 5) continuous intent to use. Each one has got a value of 3 , $3,3,3$, and 3 , respectively.

\subsection{Reliability and convergent validity assessment}

Assessed reliability using Cronbach's alpha value was measured, where the alpha value of Cronbach for all construction products should be greater than 0.70 . The authors tested the measurement scales where all item loadings met 0.7 benchmarks. Also, the Composite Reliabilities (CR) should exceed 0.7, and as indicated by Tawafak [30], the same should be with the Extracted Average Variance (AVE). The results from Table 3 showed the artifacts, their loading, the AVE, Alpha, and CR values that in the measurement model, they exceeded the proposed threshold values. Table 3: Loading products and reliability should be greater than 0.50 for each build.

Table 3. Loading products and reliability

\begin{tabular}{|c|c|c|c|c|c|}
\hline Construct & Item & Loading & Alpha & CR & (AVE) \\
\hline \multirow{3}{*}{ Academic Performance } & AP1 & 1.000 & \multirow{3}{*}{1.000} & \multirow{3}{*}{1.000} & \multirow{3}{*}{1.000} \\
\hline & AP2 & 0.580 & & & \\
\hline & AP3 & 0.702 & & & \\
\hline \multirow{3}{*}{ Behavior Intention } & BI1 & 0.937 & \multirow{3}{*}{0.814} & \multirow{3}{*}{0.813} & \multirow{3}{*}{0.689} \\
\hline & $\mathrm{BI} 2$ & 0.707 & & & \\
\hline & $\mathrm{BI} 3$ & 0.673 & & & \\
\hline \multirow{3}{*}{ Effectiveness } & EF1 & 0.630 & \multirow{3}{*}{0.754} & \multirow{3}{*}{0.807} & \multirow{3}{*}{0.680} \\
\hline & EF2 & 0.725 & & & \\
\hline & EF3 & 0.913 & & & \\
\hline \multirow{2}{*}{ Perceived Ease of Use } & PEOU1 & 0.832 & \multirow[b]{2}{*}{0.709} & \multirow[b]{2}{*}{0.826} & \multirow[b]{2}{*}{0.704} \\
\hline & PEOU2 & 0.846 & & & \\
\hline \multirow{2}{*}{ Student Satisfaction } & SS1 & 0.849 & \multirow{2}{*}{0.813} & \multirow{2}{*}{0.826} & \multirow{2}{*}{0.704} \\
\hline & SS2 & 0.828 & & & \\
\hline \multirow{4}{*}{ Perceived Usefulness } & PU1 & 0.765 & \multirow{4}{*}{0.943} & \multirow{4}{*}{0.904} & \multirow{4}{*}{0.703} \\
\hline & PU2 & 0.908 & & & \\
\hline & PU3 & 0.823 & & & \\
\hline & PU4 & 0.851 & & & \\
\hline \multirow{4}{*}{ Course Content } & $\mathrm{CC} 1$ & 1.000 & \multirow{4}{*}{0.884} & \multirow{4}{*}{1.000} & \multirow{4}{*}{1.000} \\
\hline & $\mathrm{CC} 2$ & 0.592 & & & \\
\hline & $\mathrm{CC} 3$ & 0.627 & & & \\
\hline & $\mathrm{CC} 4$ & 0.638 & & & \\
\hline \multirow{3}{*}{ Continuous Intention to Use } & CI1 & 0.873 & \multirow{3}{*}{0.883} & \multirow{3}{*}{0.875} & \multirow{3}{*}{0.700} \\
\hline & $\mathrm{CI} 2$ & 0.868 & & & \\
\hline & $\mathrm{CI} 3$ & 0.765 & & & \\
\hline
\end{tabular}




\subsection{Path value results}

The following Table explains the accepted parts and the not supported parts of the hypothesis's relationships. (Note: * $\mathrm{P}<0.001$ ).

Table 4. Path coefficient and $\beta$ results

\begin{tabular}{|l|c|c|l|}
\hline \multicolumn{1}{|c|}{ Relationship } & $\boldsymbol{\beta}$ & P-value & \multicolumn{1}{|c|}{ Remarks } \\
\hline H1-Perceived Ease Of Use $\rightarrow$ Perceived Usefulness & 0.393 & 0.000 & Accepted \\
\hline H2-Perceived Usefulness $\rightarrow$ Behavioral Intention & 0.293 & 0.001 & Accepted \\
\hline H3-Perceived Ease Of Use $\rightarrow$ Behavioral Intention & 0.302 & $0.013^{*}$ & Accepted \\
\hline H4-Perceived Usefulness $\rightarrow$ Student Satisfaction & 0.326 & 0.000 & Accepted \\
\hline H5-Perceived Ease Of Use $\rightarrow$ Student Satisfaction & 0.150 & $0.057^{*}$ & Accepted \\
\hline H6-Course Content $\rightarrow$ Effectiveness & 0.293 & 0.000 & Accepted \\
\hline H7-Behavioural Intention $\rightarrow$ Academic Performance & 0.360 & 0.000 & Accepted \\
\hline H8-Academic Performance $\rightarrow$ Continuous Intention to Use & 0.152 & $0.021^{*}$ & Accepted \\
\hline H9-Effectiveness $\rightarrow$ Continuous Intention to Use & 0.420 & 0.000 & Accepted \\
\hline H10-Student satisfaction $\rightarrow$ Continuous Intention to Use & 0.192 & 0.000 & Accepted \\
\hline
\end{tabular}

H1 leads to a significant correlation between perceived ease of use and perceived usefulness, where the direction between perceived ease of use and perceived usefulness is defined $(\beta=0.393, p<0.000)$, indicating that the perceived ease of use enhances the perceived usefulness of the acceptance model. It is reinforced by the hypothesis-relevant product $(\beta=0.293, \mathrm{p}<0.001)$, which means that the perceived utility positively relates to the behavioral intention of using the acceptance model. $\mathrm{H} 2$ leads to an influential association between perceived utility and behavioral intent. A significant link between perceived ease of use and behavioral intent is referred to as 3 . H3. If an upbeat relationship shows $(\beta=0.302, \mathrm{p}<0.013)$, it indicates that the perceived ease of use is positively related to the behavioral intention to use the acceptance model. H4 leads to a substantial positive link between perceived utility and student satisfaction.

H5 leads to a strong association between perceived ease of use and students' satisfaction, with values $(\beta=0.15, \mathrm{p}<0.057)$ implying that perceived ease of use significantly affects the acceptance model's student satisfaction. H6 leads to a significant positive association between course content and outcomes, where the positive correlation $(\beta=0.293, p<0.000)$ indicates that the course content significantly affects the effectiveness of the acceptance model. $\mathrm{H} 7$ leads to a significant correlation between behavioral intention and academic performance $(\beta=0.360, \mathrm{p}<0.000)$, indicating a positive link between behavioral intention and academic performance, where academic performance is strongly related to behavioral intention. The result of $\mathrm{H} 8$ is a significant correlation between academic performance and continuous value intention $(\beta=0.152, p<0.021)$, indicating a positive association between academic performance and continuous value intention.

\subsection{Predictive relevance Q2and F2}

The blindfolding technique conducted using Smart PLS to generate Q2 and F2 values for all independent factors. Thus, all Q2 matters should be above zero, suggesting a 
predictive relevance as recommended by Hair et al. (2013). Therefore, the current path model is inferred to have predictive relevance for the independent factors, as presented in Table 4.10. Likewise, F2 values of independent factors above 0.018 indicate a small effect, 0.15 indicates medium effects, and 0.815 indicates there is a large effect on the independent factors and the dependent factors (Hair et al., 2013). The results of the F2 and Q2 values for the model presented in Table 4.10.

Table 5. Path coefficient, $\mathrm{f} 2$, and $\mathrm{Q} 2$ results

\begin{tabular}{|l|c|c|c|l|}
\hline \multicolumn{1}{|c|}{ Relationship } & $\begin{array}{c}\text { Path } \\
\text { coefficient }\end{array}$ & F2 & Q2 & Remarks \\
\hline Perceived Ease Of Use $\rightarrow$ Perceived Usefulness & 0.393 & 0.150 & 0.582 & Supported \\
\hline Perceived Usefulness $\rightarrow$ Behavioral Intention & 0.293 & 0.245 & 0.636 & Supported \\
\hline Perceived Ease Of Use $\rightarrow$ Behavioral Intention & 0.302 & 0.200 & 0.544 & Supported \\
\hline Perceived Usefulness $\rightarrow$ Student Satisfaction & 0.326 & 0.400 & 0.145 & Supported \\
\hline Perceived Ease Of Use $\rightarrow$ Student Satisfaction & 0.150 & 0.240 & 0.372 & Supported \\
\hline Course Content $\rightarrow$ Effectiveness & 0.293 & 0.190 & 0.815 & Supported \\
\hline Behavioral Intention $\rightarrow$ Academic Performance & 0.360 & 0.236 & 0.545 & Supported \\
\hline Academic Performance $\rightarrow$ Continuous Intention to Use & 0.152 & 0.190 & 0.160 & Supported \\
\hline Effectiveness Continuous $\rightarrow$ Intention to Use & 0.420 & 0.323 & 0.303 & Supported \\
\hline Student Satisfaction $\rightarrow$ Continuous Intention to Use & 0.192 & 0.170 & 0.118 & Supported \\
\hline
\end{tabular}

\section{Conclusion}

This research provides a theoretical contribution by extending TAM and part of the ECT model constructs and associated items to improve the learning process through the combined model for technology validation. The model also identifies how the course contents act as independent factors to influence the system CI of use. In summary, the findings from this study provide the following significant contributions:

This research developed the combined model based on the combined models' factors that directly or indirectly influence $\mathrm{CI}$ in a higher educational institution. This contribution generated sub-contributions as follows:

This research identified the relationships between selected elements. In its essential variables and part of ECT model variables, it also used the TAM model to combine the combined model. This study developed a combined model of continuous intention to use the e-learning system by linking the e-learning system (PU, PEOU, CC) to intermediate factors consisting of e-learning systems (BI, AP, EFF, SS). The proposed four new elements based on e-learning CI analogous to both TAM and part of the ECT model used to evaluate the use of the combined model as an e-learning CI model. Lastly, this research-validated the results generated from the modified TAM, part of ECT models by a proposed combined model for continuous intention to use a system. The authors extended the application learning system to a more functional and interactive approach to producing efficient learning results for students. 


\section{References}

[1] Engelbrecht, E. (2003). A look at e-learning models: investigating their value for de-veloping an e-learning strategy. Progressio, 25(2), 38-47.

[2] MacDonald, C. J., Stodel, E. J., Farres, L. G., Breithaupt, K., \& Gabriel, M. A. (2001). The demand-driven learning model: A framework for web-based learning. The Internet and Higher Education, 4(1), 9-30. https://doi.org/10.1016/s1096-7516(01)00045-8

[3] Tawafak R. M., Mohammed M. N, and Arshah R. B. A, "Review on the Effect of Stu-dent Learning Outcome and Teaching Technology in Omani's Higher Education Institu-tion's Academic Accreditation Process," in International Conference on Software and Computer Applications, 2018. https://doi.org/10.1145/3185089.3185108

[4] Wu, B., \& Zhang, C. (2014). An empirical study on continuance intentions towards E-Learning 2.0 systems. Behaviour \& Information Technology, 33(10), 1027-1038. https://doi.org/ 10.1080/0144929x.2014.934291

[5] Strang, K. D. (2013). University accreditation and benchmarking: Pedagogy that in-creases student achievement.

[6] Hone, K. S., \& El Said, G. R. (2016). Exploring the factors affecting MOOC retention: A survey study. Computers \& Education, 98, 157-168. https://doi.org/10.1016/j.compedu. 2016.03.016

[7] Huang, L., Zhang, J., \& Liu, Y. (2017). Antecedents of student MOOC revisit inten-tion: Moderation effect of course difficulty. International Journal of Information Man-agement, 37(2), 84-91. https://doi.org/10.1016/j.ijinfomgt.2016.12.002

[8] Tawafak, Ragad M., Awanis BT Romli, and Ruzaini Bin Abdullah Arshah. "Continued Intention to use UCOM: Four factors for integrating with a technology acceptance model to moderate the Satisfaction of Learning." IEEE Access 6 (2018): 66481-66498. https://doi. org/10.1109/access.2018.2877760

[9] Joo, Y. J., So, H. J., \& Kim, N. H. (2018). Examination of relationships among stu-dents' self-determination, technology acceptance, satisfaction, and continuance intention to use KMOOCs. Computers \& Education. https://doi.org/10.1016/j.compedu.2018.01.003

[10] Ioannou, A., Brown, S., \& Artino, A. R. (2015). Wikis and forums for collaborative problem-based activity: A systematic comparison of learners' interactions. The Internet and Higher Education, 24, 35-45. https://doi.org/10.1016/j.iheduc.2014.09.001

[11] Goodhue, D.L., Thompson, R.L., 1995. Task-technology fit and individual perfor-mance. MIS Q. 19 (2), 213-236. https://doi.org/10.2307/249689

[12] Tawafak, Ragad M., et al. "Technology enhancement learning reflection on improving students' satisfaction in Omani universities." Advanced Science Letters 24.10 (2018): 77517757. https://doi.org/10.1166/asl.2018.13012

[13] Alraimi, K. M., Zo, H., \& Ciganek, A. P. (2015). Understanding the MOOCs continu-ance: The role of openness and reputation. Computers \& Education, 80, 28-38. https://doi.org/10. 1016/j.compedu.2014.08.006

[14] Tawafak, R. M., Romli, A., Malik, S. I., Shakir, M., \& Alfarsi, G. M. (2019). A sys-tematic review of personalized learning: Comparison between E-learning and learning by coursework program in Oman. International Journal of Emerging Technologies in Learn-ing (iJET), 14(09), 93-104. https://doi.org/10.3991/ijet.v14i09.10421

[15] Karnouskos, S. (2017). Massive open online courses (MOOCs) as an enabler for competent employees and innovation in the industry. Computers in Industry, 91, 1-10. https://doi.org/ 10.1016/j.compind.2017.05.001

[16] Davis, F. D. (1989). Perceived usefulness, perceived ease of use, and user acceptance of information technology. MIS Quarterly, 319-340. https://doi.org/10.2307/249008 
[17] Lee, C., Yeung, A. S., \& Ip, T. (2017). University English language learners' readiness to use computer technology for self-directed learning. System, 67, 99-110. https://doi.org/ 10.1016/j.system.2017.05.001

[18] Eldow, A., Shakir, M., Talab, M. A., Muttar, A. K., \& TAWAFAK, R. M. (2006). Literature Review of Authentication Layer for Public Cloud Computing: A Meta-Analysis.

[19] Junglas, I., Abraham, C., \& Watson, R. T. (2008). Task-technology fit for mobile lo-catable information systems. Decision Support Systems, 45(4), 1046-1057. https://doi.org/10.1016/ j.dss.2008.02.007

[20] Tawafak, Ragad M., et al. "Framework design of university communication model (UCOM) to enhance continuous intentions in teaching and e-learning process." Education and Information Technologies (2019): 1-27. https://doi.org/10.1007/s10639-019-09984-2

[21] Tawafak, Ragad M., Awanis BT Romli, and Maryam Alsinani. "E-learning system of UCOM for improving student assessment feedback in Oman higher education." Educa-tion and Information Technologies 24.2 (2019): 1311-1335. https://doi.org/10.1007/s10639-018$\underline{9833-0}$

[22] Venkatesh, V., and Davis, F.D. (2000). A theoretical extension of the technology acceptance model: Four longitudinal field studies. Management of Science. 46(2), 186-204. https://doi.org/10.1287/mnsc.46.2.186.11926

[23] De Wever, B., Hämäläinen, R., Voet, M., \& Gielen, M. (2015). A wiki task for first-year university students: The effect of scripting students' collaboration. The Internet and Higher Education, 25, 37-44. https://doi.org/10.1016/j.iheduc.2014.12.002

[24] Schmid, R. F., Bernard, R. M., Borokhovski, E., Tamim, R. M., Abrami, P. C., Surkes, M. A., \& Woods, J. (2014). The effects of technology use in postsecondary education: A metaanalysis of classroom applications. Computers \& Education, 72, 271-291. https://doi.org/10. 1016/j.compedu.2013.11.002

[25] Liu, L. (2005). Evaluating online learning applications: Development of quality-related models. International Journal of Information and Communication Technology Education (IJICTE), 1(3), 21-35. https://doi.org/10.4018/jicte.2005070102

[26] Tawafak, Ragad M., Sohail Iqbal Malik, and Ghaliya Alfarsi. "Development of Framework from Adapted TAM with MOOC Platform for Continuity Intention." Devel-opment 29.1 (2020): 1681-1691.

[27] Tawafak, R. M., Romli, A. M., \& Alsinani, M. J. (2019). Student assessment feedback effectiveness model for enhancing teaching method and developing academic perfor-mance. International Journal of Information and Communication Technology Education (IJICTE), 15(3), 75-88. https://doi.org/10.4018/ijicte.2019070106

[28] Tawafak, R. M., Romli, A. B., bin Abdullah Arshah, R., \& Almaroof, R. A. S. (2018). Assessing the impact of technology learning and assessment method on academic per-formance. EURASIA Journal of Mathematics, Science and Technology Education, 14(6), 2241-2254. https://doi.org/10.29333/ejmste/87117

[29] Tawafak, F. R. M. The Comprehension Theories Of Continuous Intention To Use Tel With E-Learning Models In Educations. Table of Content Id Title Author Page No., 41.

[30] Tawafak, R. M., Romli, A., \& Arshah, R. A. (2019, August). E-learning prospect on improving academic performance in Omani Universities. In IOP Conference Series: Mate-rials Science and Engineering (Vol. 551, No. 1, p. 012033). IOP Publishing. https://doi.org/10. $\underline{\text { 1088/1757-899x/551/1/012033 }}$

[31] Tawafak, R. M., Malik, S. I., \& Alfarsi, G. (2020). Development of Framework from Adapted TAM with MOOC Platform for Continuity Intention. Development, 29(1), 16811691. 
[32] Papadakis, S. (2018). Evaluating pre-service teachers' acceptance of mobile devices with regards to their age and gender: a case study in Greece. International Journal of Mobile Learning and Organisation, 12(4), 336-352. https://doi.org/10.1504/ijmlo.2018.10013372

[33] Tawafak, R. M., Romli, A. B., \& Arshah, R. B. A. (2019, February). E-learning Model for Students' Satisfaction in Higher Education Universities. In 2019 International Confer-ence on Fourth Industrial Revolution (ICFIR) (pp. 1-6). IEEE. https://doi.org/10.1109/icfir. $\underline{2019.8894778}$

[34] Papadakis, S., Kalogiannakis, M., Orfanakis, V., \& Zaranis, N. (2017). The Appropriateness of Scratch and App Inventor as Educational Environments for Teaching Introductory Programming in Primary and Secondary Education. International Journal of Web-Based Learning and Teaching Technologies (IJWLTT), 12(4), 58-77. https://doi.org/10.4018/ ijwltt.2017100106

[35] Vidakis, N.; Barianos, A.; Trampas, A.; Papadakis, Stamatios; Kalogiannakis, M. and Vassilakis, K. (2019). Generating Education in-Game Data: The Case of an Ancient Thea-tre Serious Game.In Proceedings of the 11th International Conference on Computer Sup-ported Education - Volume 1: CSEDU, ISBN 978-989-758-367-4, pages 36-43. https://doi.org/ $\underline{10.5220 / 0007810800360043}$

[36] Papadakis, S.; Vaiopoulou, J.; Kalogiannakis, M.; Stamovlasis, D. Developing and Ex-ploring an Evaluation Tool for Educational Apps (ETEA.) Targeting Kindergarten Chil-dren. Sustainability, 2020, 12, 4201. https://doi.org/10.3390/su12104201

[37] Papadakis, S., Kalogiannakis, M., Sifaki, E., \& Vidakis, N. (2017). Access Moodle Using Smart Mobile Phones. A Case Study in a Greek University. In Proceedings of the 6th International Conference and Second International Conference (ArtsIT 2017, DLI 2017), 'Interactivity, Game Creation, Design, Learning, and Innovation'. Heraklion, Crete, Greece, October 30-31, 2017. https://doi.org/10.1007/978-3-319-76908-0

[38] ALFarsi, G., Jabbar, J., Tawafak, R. M., Iqbal, S., Alsidiri, A., Alsinani, M., \& bte Sulaiman, H. (2020). Mobile Application System Supported BUC Students Services and Learning. https://doi.org/10.3991/ijim.v14i09.12053

[39] Tawafak, R. M., Alfarsi, G., AlNuaimi, M. N., Eldow, A., Malik, S. I., \& Shakir, M. (2020, April). Model of Faculty Experience in E-Learning Student Satisfaction. In 2020 International Conference on Computer Science and Software Engineering (CSASE) (pp. 83-87). IEEE. https://doi.org/10.1109/csase48920.2020.9142071

[40] Tawafak, R. M., AlSideir, A., Alfarsi, G., Al-Nuaimi, M. N., Malik, S. I., \& Jabbar, J. (2019). E-learning Vs. Traditional Learning for Learners Satisfaction. E-learning, 29(3), 388-397.

[41] Jabbar, J., Malik, S. I., AlFarsi, G., \& Tawafak, R. M. The Impact of WhatsApp on Employees in Higher Education. In Recent Advances in Intelligent Systems and Smart Applications (pp. 639-651). Springer, Cham. https://doi.org/10.1007/978-3-030-47411-9 34

[42] Alfarsi, G., Sulaiman, H., Tawafak, R. M., Malik, S., Jabbar, J., \& Alsidiri, A. (2019). A Study of Learning Management System with E-Learning.

[43] Tawafak, R., Romli, A., Malik, S., \& Shakir, M. (2020). IT Governance Impact on Academic Performance Development. International Journal of Emerging Technologies in Learning (iJET), 15(18), 73-85. https://doi.org/10.3991/ijet.v15i18.15367

[44] Syaifudin, Y. W., Yunhasnawa, Y., Pramitarini, Y., Setiawan, A., Rohadi, E., \& Sapu-tra, P. Y. (2020). A Proposed Framework of Campus-Oriented Online Text Messaging System. International Journal of Interactive Mobile Technologies, 14(16). https://doi.org/10.3991/ ijim.v14i16.11454 
[45] Malik, S., Al-Emran, M., Mathew, R., Tawafak, R., \& AlFarsi, G. (2020). Comparison of E-Learning, M-Learning and Game-based Learning in Programming Education-A Gendered Analysis. International Journal of Emerging Technologies in Learning (iJET), 15(15), 133-146. https://doi.org/10.3991/ijet.v15i15.14503

[46] Tatnall, A. (2020). Editorial for EAIT issue 2, 2020. Education and Information Technologies, 25(2), 647-657. https://doi.org/10.1007/s10639-020-10135-1

[47] Lezzar, F., Benmerzoug, D., \& Kitouni, I. (2020). IoT for Monitoring and Control of Water Quality Parameters. International Journal of Interactive Mobile Technologies, 14(16). https://doi.org/10.3991/ijim.v14i16.15783

[48] Utomo, B., Wibowo, A. T., Ridwan, M., Izzuddin, M. A., Gumelar, A. B., \& Arifin, S. (2020). Enhanced of Attendance Records Technology used Geospatial Retrieval based on Crossing Number. International Journal of Interactive Mobile Technologies, 14(16). https://doi.org/10.3991/ijim.v14i16.13911

\section{Authors}

Ragad M Tawafak has Ph.D. Degree in computer science, 2020 Malaysia. She is an expert in E-Learning, Mobile Application, Knowledge Management, etc.

Ghaliya Alfarsi: has MSc. Degree in computer science, 2015, Oman. She is an expert in E-Learning, Mobile Application, Knowledge Management, etc.

Jasiya Jabbar is an expert in E-Learning, Mobile Application, Knowledge Management, etc.

Sohail Iqbal Malik has Ph.D. Degree in computer science, 2016 Australia. Also, he is an expert in E-Learning, Mobile Application, Knowledge Management, etc.

Roy Mathew is a Ph.D. in Computer science, 2016, India. He is an expert in ELearning, Mobile Application, Knowledge Management, etc.

Mohammed Waseem Ashfque has is post-graduation in Computer Science from Dr. Babasaheb Ambedkar Marathwada University, India. His research domain is Artificial intelligence, Machine learning, and Deep Learning. He has sound experience in teaching at various colleges and Universities.

Maryam Nasser AL-Nuaimi has completed her Ph.D. degree in 2019 from SultanQaboos University. Her research interests e-learning in higher education.

Abdalla Eldow has Ph.D. Degree in computer science, 2013, Sudan. Also, he is an expert in E-Learning, Mobile Application, Knowledge Management, etc.

Article submitted 2020-09-30. Resubmitted 2020-12-06. Final acceptance 2020-12-06. Final version published as submitted by the authors. 